\title{
Preserved Haptic Shape Processing after Bilateral LOC Lesions
}

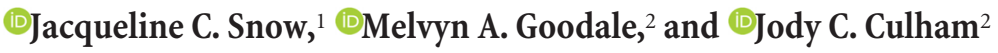 \\ ${ }^{1}$ Department of Psychology, University of Nevada, Reno, Nevada 89557, and ${ }^{2}$ The Brain and Mind Institute, The Natural Sciences Centre, Department of \\ Psychology, University of Western Ontario, London, Ontario N6A5B7, Canada
}

The visual and haptic perceptual systems are understood to share a common neural representation of object shape. A region thought to be critical for recognizing visual and haptic shape information is the lateral occipital complex (LOC). We investigated whether LOC is essential for haptic shape recognition in humans by studying behavioral responses and brain activation for haptically explored objects in a patient (M.C.) with bilateral lesions of the occipitotemporal cortex, including LOC. Despite severe deficits in recognizing objects using vision, M.C. was able to accurately recognize objects via touch. M.C.'s psychophysical response profile to haptically explored shapes was also indistinguishable from controls. Using fMRI, M.C. showed no object-selective visual or haptic responses in LOC, but her pattern of haptic activation in other brain regions was remarkably similar to healthy controls. Although LOC is routinely active during visual and haptic shape recognition tasks, it is not essential for haptic recognition of object shape.

Key words: haptic; lateral occipital complex; neuropsychological fMRI; shape perception

\section{Significance Statement}

The lateral occipital complex (LOC) is a brain region regarded to be critical for recognizing object shape, both in vision and in touch. However, causal evidence linking LOC with haptic shape processing is lacking. We studied recognition performance, psychophysical sensitivity, and brain response to touched objects, in a patient (M.C.) with extensive lesions involving LOC bilaterally. Despite being severely impaired in visual shape recognition, M.C. was able to identify objects via touch and she showed normal sensitivity to a haptic shape illusion. M.C.'s brain response to touched objects in areas of undamaged cortex was also very similar to that observed in neurologically healthy controls. These results demonstrate that LOC is not necessary for recognizing objects via touch.

\section{Introduction}

The brain region understood to be critical for visual shape perception is the lateral occipital complex (LOC) within the human ventral visual processing stream (Malach et al., 1995, GrillSpector, 2003). Patients with LOC damage show striking behavioral impairments in their ability to recognize objects in the context of otherwise normal basic visual function, a condition known as visual form agnosia (Benson and Greenberg, 1969; Farah, 1990; James et al., 2003; Allen and Humphreys, 2009; Konen et al., 2011). Several imaging studies have reported that

Received March 1, 2014; revised Aug. 1, 2015; accepted Sept. 2, 2015.

Author contributions: J.C.S., M.A.G., and J.C.C. designed research; J.C.S. performed research; J.C.S. analyzed data; J.C.S., M.A.G., and J.C.C. wrote the paper.

This work was supported by the Canadian Institutes of Health Research (Operating Grant to M.A.G.) and The Natural Sciences and Engineering Research Council of Canada (Discovery Grant and E.W.R. Steacie Memorial Fellowship to J.C.C.). We thank Marlene Behrmann for helpful comments on the manuscript and Alex Coros and Kevin Stubbs for assistance with data analysis and reconstruction of M.C.'s cortical surface.

Correspondence should be addressed to Jacqueline C. Snow, Department of Psychology, University of Nevada, 1664 N. Virginia St., Reno, NV 89557. E-mail: jacqueline.c.snow@gmail.com or snow@unr.edu.

DOI:10.1523/JNEUROSCI.0859-14.2015

Copyright $\odot 2015$ the authors $\quad 0270-6474 / 15 / 3513745-16 \$ 15.00 / 0$ the LOC is also involved in haptic shape recognition. In particular, the subdivision of the LOC sometimes termed the "lateraloccipital tactile-visual region" $\left(\mathrm{LO}_{\mathrm{TV}}\right)$ is argued to contain multisensory visuohaptic neural populations (Amedi et al., 2001, 2005) and constitutes a locus, or one of several loci, critical for high-level multimodal visuohaptic shape representation (Amedi et al., 2002, 2005; James et al., 2005; James et al., 2007; Lacey et al., 2009; James and Kim, 2010; Lucan et al., 2010; Lacey and Sathian, 2011).

Imaging data alone provide correlational evidence linking LOC with haptic shape processing, but causal evidence from transcranial magnetic stimulation (TMS) and patient studies is lacking. In vision, applying TMS over LOC produces subtle effects on response times (Stewart et al., 2001; Chouinard et al., 2009) and accuracy (Pitcher et al., 2009). One study has reported that LOC TMS influenced a haptic shape illusion (Mancini et al., 2011) although, puzzlingly, this effect was observed with ipsilateral rather than contralateral stimulation. Together with fMRI results in vision demonstrating that fMRI responses in the LOC correlate strongly with the magnitude of the illusion (Weidner and Fink, 2007), Mancini et al., (2011) argued that the LOC is a 
region that is necessary for building shared visuohaptic shape representations. In contrast to the subtle effects of TMS, neuropsychological studies of patients with LOC lesions have documented massive deficits in visual object recognition and provide undisputed evidence for the critical role of LOC in visual shape processing; even small infarcts confined to LO are sufficient to produce severe impairments in visually recognizing everyday objects under free-viewing conditions, and a clear bilateral reduction in neural responsivity to visually presented objects as measured by fMRI (Konen et al., 2011). The available evidence from neuropsychology links haptic shape recognition deficits with damage to parietal or insular cortex (Morin et al., 1984; Reed et al., 1996; Hömke et al., 2009). There have been two additional single-case studies of patients with haptic recognition deficits in association with damage to regions of temporal cortex (Feinberg et al., 1986; Ohtake et al., 2001); however, the evidence for LOC involvement in these patients is, at best, inconclusive.

Here, we investigated whether LOC is necessary for haptic object recognition by studying the behavior and brain activation of a patient, M.C., who has extensive lesions involving the occipitotemporal cortex that include the LOC bilaterally. We reasoned that, if the LOC is necessary for recognizing object shape via touch as well as in vision, then lesions of LOC should result in an amodal object agnosia across both the visual and the haptic domains - and a corresponding attenuation of fMRI activation to both visually and haptically presented objects, even in spared areas. We also examined M.C.'s susceptibility to the Müller-Lyer illusion (MLI) in vision and touch. If LOC is critical for eliciting the illusion via touch (Mancini et al., 2011), then bilateral lesions to the LOC should result in a severe attenuation in illusion magnitude in both sensory modalities.

\section{Materials and Methods}

\section{Participants}

M.C. is a right-handed woman born in 1969 (42 years old at the time of testing) who worked as a secretary at a local hospital eye clinic. At age 30, M.C. suffered hypotension as a result of a respiratory infection and fell into coma for $59 \mathrm{~d}$, during which time she suffered a stroke. A CT scan initially revealed bilateral occipital lobe infarctions. Upon emergence from coma, M.C. reported having "no useful vision" and static perimetry testing conducted by an ophthalmologist showed her to be totally blind. She was later found to have some residual visual sensitivity for moving stimuli (i.e., Riddoch phenomenon; Riddoch, 1917). Over the ensuing years after the stroke, M.C. reported a gradual improvement in her visual abilities, particularly for moving stimuli. Her phenomenological reports have been substantiated by parallel follow-up ophthalmological visual perimetry tests that have generally reported a failure to detect static targets, but some preserved sensitivity for moving targets. Recent formal ophthalmological assessment (April of 2011, 12 years after the stroke) revealed spared visual sensitivity within the upper left visual quadrant ( $\sim 20-70$ degrees eccentricity) and a small region within the lower right visual quadrant ( $\sim 20-40$ degrees eccentricity) on Goldman kinetic perimetry testing. M.C. presented as an intelligent, cooperative woman who showed no sign of unilateral neglect nor evidence of tactile or auditory extinction upon bilateral simultaneous stimulation. Highresolution structural MRI of M.C.'s brain (Fig. 1) revealed an extensive bilateral infarction affecting the occipitotemporal lobes and extending dorsally into right posterior parietal cortex. The only remaining occipital lobe tissue is a small region at the rostral end of the calcarine sulcus (corresponding to the peripheral visual field).

Patient M.C. and 12 neurologically healthy age-matched control subjects (all right-handed, mean age $=40, \mathrm{SD}=4$, age range, 36-47) participated in the haptic fMRI experiment. The fMRI study was performed at the Robarts Research Institute at Western University. M.C. and seven of the 12 controls who participated in the haptic fMRI experiment later took part in a psychophysical experiment examining sensitivity to the
MLI in vision and touch. Participants gave informed written consent for participation in each of the studies, which were approved by the Western University Health Sciences Research Ethics Board.

\section{Stimuli}

Prescreening tasks. The following materials were used for haptic prescreening with patient M.C. For testing texture perception, four pieces of sandpaper of gradually increasing roughness and eight different textured materials (fur, burlap, cotton, foam, lace, velvet, tissue, and plastic) were used. Haptic shape recognition performance was first examined using a set of three basic shapes (circle, square, and triangle) at three different sizes (small, medium, large). Haptic recognition of complex shapes was examined using a set of 110 different real-world 3D everyday objects. Haptic recognition performance for complex abstract shapes was later assessed using a set of novel 3D clay objects (James et al., 2002; James et al., 2005). In this task, M.C. was allowed to explore a sample object for $3 \mathrm{~s}$ and was then given a test object and asked whether it was the same or different (James et al., 2005). Response times to identify haptically presented objects were also compared between M.C. and seven of the agematched controls using a set of 10 everyday items, different from those used in the fMRI study. Participants palpated each object with both hands and were instructed to name the item as soon as it was recognized. fMRI experiments: visual and haptic object perception. Stimuli for the main haptic fMRI experiment were a set of 50 solid 3D real-world natural and man-made objects that could be explored using one hand (e.g., toothbrush, tennis ball, lemon). The textures were 30 nonrigid amorphous sheets of different types of material (e.g., fur, leather, plastic).

Neural responses to visual objects were tested in M.C. and one of the 12 age-matched control observers using a standard visual object localizer task. fMRI responses were contrasted for epochs of colored common objects versus scrambled versions of the same stimuli. Photographs, presented in full color, were drawn from the Hemera Photo-Objects image database. Objectselective responses were examined by contrasting fMRI responses for object blocks with those for scrambled blocks. Each epoch lasted $16 \mathrm{~s}$ and total run duration was $6 \mathrm{~min} 40 \mathrm{~s}$. M.C. and the age-matched control each completed two runs while passively viewing the stimuli. Patient M.C. was unable to report the identity of any of the stimulus objects in the visual localizer task. Motion sensitivity was investigated in M.C. by contrasting a moving checkerboard (which reversed direction between expansion and contraction every $2 \mathrm{~s})$ with a stationary checkerboard ( $16^{\circ}$ visual angle). Motion sensitivity data for M.C. were collected on a Siemens 3T Allegra scanner at Maastricht University [single-channel head coil, repetition time (TR) $=2 \mathrm{~s} ; 3.5 \mathrm{~mm}$ isotropic resolution; 32 slices]. Each run ( $5 \mathrm{~min}, 20 \mathrm{~s}$ ) was composed of $16 \mathrm{~s}$ epochs of a moving checkerboard ( 6 epochs), a stationary checkerboard (6 epochs), and a blank screen (7 epochs). Two runs were collected during each of two separate sessions and combined using intersession alignment. These data will be presented in full in a later, separate manuscript, but are shown here for comparing the position of a motion-selective region in the ascending limb of the inferior temporal sulcus in medial temporal cortex (dorsal to LO) known as MT+, with a separate middle temporal gyrus (MTG) focus observed in the haptic fMRI task (see Fig. 8).

Psychophysical experiments with the Müller-Lyer stimulus. The MüllerLyer stimuli were embedded geometrical figures that were engraved into square, dual-color black-and-white acrylic plates (see Fig. 9). The plates were cut to a uniform size of $127 \times 127 \mathrm{~mm}$ ( 5 inch squares). Visually, the stimuli appeared black against a white background. The horizontal shaft (central line) of one figure was terminated with inward-pointing arrows (the "standard") and the shaft of the other terminated with outward-pointing arrows (the "comparison"). The two figures were aligned vertically and centered upon the midline of each plate. The width of the stimulus lines was $2 \mathrm{~mm}$ and each line was cut to a depth of $2 \mathrm{~mm}$ using a square-end mill. The standard and comparison figures were positioned $20 \mathrm{~mm}$ apart from nearest edge to edge. The shaft of the standard was $30 \mathrm{~mm}$ in length and each outgoing fin was $10 \mathrm{~mm}$ long. The angle between the fins of the comparison figure was $90^{\circ}$. The shaft of the comparison varied in length from 24 to $48 \mathrm{~mm}$ in increments of $2 \mathrm{~mm}$, which, when paired with the standard, yielded a total of 13 different stimulus plates. The angle subtended by the arrowhead on the ingoing comparison figure was $90^{\circ}$. 




Figure 1. $\quad \boldsymbol{a}$, High-resolution structural MRI of patient M.C.'s brain. M.C.'s lesion is displayed in a series of consecutive ascending axial slices from ventral on left to dorsal on right, with the relative slice positioning shown (inset, lower right). M.C.'s lesion encompasses most of visual cortex, posterior lateral and ventral temporal cortex, and part of right posterior parietal cortex. Importantly, M.C.'s lesion includes visual-object-selective area LOC. All MRl images are displayed in neurological convention (LH on left side of image). $\boldsymbol{b}$, fMRI response to visually-presented colored objects versus scrambled control stimuli in patient M.C. (left) versus an age-matched neurologically intact observer (right). M.C. showed virtually no neural response to visual objects ( $p<0.001$, activation shown in orange). Only a few small clusters were observed within the left mid-inferior temporal gyrus (mITG), left dorsal intraparietal sulcus (dIPS), right precentral sulcus (preCS), and the bilaterally in the cerebellum. There was very little increase in M.C.'s fMRI response to visual objects even at a more relaxed statistical threshold ( $p<0.01$ uncorrected; red). An age-matched control, in contrast, showed a typical pattern of strong bilateral activation extending from lateral occipital to ventral temporal cortex and dorsally into parietal cortex. The point of peak activation for visual objects in the control is marked with a black crosshair (Talairach $z=-12$ ). For comparative purposes, the corresponding point is also demarcated with a white crosshair on M.C.'s anatomical image. Although some of the objects $>$ textures activation shown for the control observer $(p<0.001)$ overlaps with regions of spared tissue within M.C.'s ventral temporal cortex, M.C. nevertheless did not show corresponding activation within the undamaged regions of cortex, suggesting that her lesion has affected regions critical for processing visual object shape (e.g., area L 0 ).

\section{Procedure and experimental design}

fMRI experiments: visual and haptic object perception. Before scanning, participants completed a haptic behavioral shape recognition task, followed immediately by an fMRI experiment designed to reveal neural responsivity to objects and textures palpated with the right hand (Fig. 2c). In the behavioral object recognition task, participants were blindfolded and subsequently presented with each of the 50 objects. Participants were instructed to name each item as quickly as possible. After completing the object recognition task, participants were placed supine within the scanner with the right hand facing upward and resting securely upon a padded surface. In the haptic fMRI experiment, participants were presented with brief sequences of objects or textures to palpate. The experiment had a blocked design with three somatosensory conditions: touching different textures (texture different condition), touching different objects (object different condition), and repeatedly touching the same object (object same condition). Each 20 s block of trials consisted of 5 consecutive somatosensory objects or textures ( $4 \mathrm{~s}$ each). Somatosensory blocks were followed by $20 \mathrm{~s}$ of rest. A $200 \mathrm{~ms}$ auditory tone was delivered via headphones to both the subject and experimenter once every $4 \mathrm{~s}$ : 1 tone signaled the onset of each $4 \mathrm{~s}$ somatosensory trial ( $n=5$ per somatosensory block) and a second tone indicated rest trials ( $n=5$ per rest block). The participant's task was to passively identify each of the objects or textures. Participants were instructed to hold the hand open and ready to receive the stimulus at the onset of the somatosensory auditory cue and to release their grasp at the end of each trial. Stimuli were placed into the subject's palm by the experimenter. Stimuli presented in each "different" object or texture somatosensory block were drawn randomly from the available pool of objects or textures without back-to-back repetitions. The fMRI experiment followed a single-case design in which ordering of real objects and conditions were identical for M.C. and each control participant. Each scan comprised a total of 12 somatosensory blocks comprising four repeats of the three somatosensory conditions. Ordering of conditions was counterbalanced such that, across scans, each condition preceded and followed all other conditions an equal number of times. An additional period of $30 \mathrm{~s}$ (12 volumes) of rest without auditory tones was collected at the start of each scan and $5 \mathrm{~s}$ (2 volumes) at the end. Each scan lasted $515 \mathrm{~s}$ (8 min, $35 \mathrm{~s}$ ). All subjects completed six scans within a single fMRI testing session (yielding a total of 24 blocks per condition). Timing of stimulus presentation was controlled using E-Prime version 1.0 software.

Psychophysical experiments: visual and haptic MLI. Patient M.C. and seven of the 12 age-matched controls completed the Müller-Lyer experiment. Each participant completed a total of 20 blocks of trials, 10 blocks using vision and 10 blocks using touch. In visual blocks, participants were instructed to inspect the figures using vision alone without touching the 
stimuli. In haptic blocks, participants were blindfolded and instructed to explore the figures using only the right index finger. The participants' task was to state verbally, using a two-alternative forced choice, whether the horizontal shaft of the figure positioned at the top was shorter or longer than that of the one below. Participants completed 13 such discrimination trials per block (totaling 130 trials using vision and 130 trials using touch). Viewing distance was set to $\sim 50 \mathrm{~cm}$ to approximate the distance of the hand from the body during haptic exploration of the figures. The order of visual and haptic blocks was counterbalanced using an ABBA design. In half of the blocks, the standard appeared above the comparison figure and, on remaining blocks, the figures were presented in the reverse configuration (180 degrees rotated). Stimulus orientation was alternated across each visual and haptic block. Trials were presented in the same order for M.C. and all controls.

\section{MRI acquisition}

Scanning in the visual and haptic shape fMRI experiments was performed on a 3 tesla $(\mathrm{T})$ Siemens Magnetom Tim Trio imaging system, with a standard 32-channel receive-only head coil configuration. For all participants, the functional data were acquired with a $\mathrm{T}^{*}$ weighted single-shot gradient-echo echoplanar imaging sequence with interleaved slice acquisition. The parameters for obtaining functional data were as follows: field of view $(\mathrm{FOV})=210$ $\mathrm{mm} \times 210 \mathrm{~mm}$; resolution $=3.3 \mathrm{~mm}$ isotropic; 46 axial slices; echo time $(\mathrm{TE})=30 \mathrm{~ms}$; $\mathrm{TR}=2500 \mathrm{~ms}$; flip angle $(\mathrm{FA})=90^{\circ}$, matrix size $=70$. A total of 206 functional volumes were collected in each scan. Functional data were aligned to high-resolution anatomical images obtained using a 3D T1-weighted MPRAGE sequence $[\mathrm{TE}=2.98 \mathrm{~ms} ; \mathrm{TR}=2300$ $\mathrm{ms}$; inversion time $(\mathrm{TI})=900 \mathrm{~ms} ; \mathrm{FA}=9^{\circ} ; 192$ contiguous slices of $1 \mathrm{~mm}$ thickness; FOV = $\left.240 \mathrm{~mm} \times(256 \mathrm{~mm})^{2}\right]$.

The visual object localizer task was conducted in a separate scanning session for both M.C. and the age-matched control participant. For the control participant, functional runs were acquired with a $\mathrm{T} 2{ }^{*}$-weighted single-shot gradient-echo echoplanar imaging sequence with interleaved slice acquisition. Scans were conducted using a standard 12-channel receive-only head coil with the following scan parameters: $\mathrm{FOV}=210 \times 210 \mathrm{~mm}$, in-plane resolution $=$ $3.3 \times 3 \mathrm{~mm}$, slice thickness $=3 \mathrm{~mm}, 33$ axial slices, $\mathrm{TE}=30 \mathrm{~ms}$, $\mathrm{TR}=$ $2000 \mathrm{~ms}, \mathrm{FA}=78^{\circ}$. Functional data were overlaid on a high-resolution anatomical image obtained using a 3D T1-weighted MPRAGE sequence identical to that used in the main haptic experiment. Patient M.C. completed the visual localizer task (only) on a $4 \mathrm{~T}$, whole-body MRI system (Varian-Siemens) system (the predecessor to the current $3 \mathrm{~T}$ magnet used for the remainder of the experiments). Functional runs were acquired with a $\mathrm{T} 2{ }^{\star}$-weighted navigator-echo-corrected, segmented spiral acquisition. Scans were conducted using a single-channel transmitreceive, cylindrical birdcage radio-frequency head coil, with the following scan gradient-echo echoplanar imaging parameters: FOV $=192 \times$ $192 \mathrm{~mm}$, in-plane resolution $=3 \times 3 \mathrm{~mm}$, slice thickness $=4 \mathrm{~mm}, 25$ axial slices, $\mathrm{TE}=20 \mathrm{~ms}, \mathrm{TR}=2000 \mathrm{~ms}, \mathrm{FA}=48^{\circ}$. M.C.'s functional data for the visual object localizer task were overlaid on a high-resolution anatomical image obtained using a 3D T1-weighted magnetizationprepared acquisition sequence with the following parameters: $\mathrm{TE}=$ b

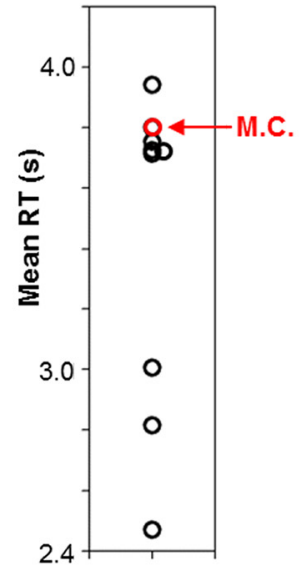



Figure 2. $\quad \boldsymbol{a}$, Behavioral object identification accuracy in M.C. Using vision (top), M.C. was unable to identify any common consecutively explored novel objects were the same or different in shape, $\boldsymbol{b}$. RTs to recognize everyday objects via touch in M.C. were similar to age-matched controls. Open circles in the vertical point plot represent mean RT for each individual. M.C.'s mean RT , was well within the range of RTs shown by controls (black circles; $t=0.23, p=0.83$ ). c, Protocol used in the main haptic (texture different), touching different objects (object different), and repeatedly touching identical objects (object same). Somatosensory blocks were interleaved with blocks of rest and the order of somatosensory conditions was counterbalanced across scans.

$0.0055 \mathrm{~s} ; \mathrm{TR}=0.76 \mathrm{~s} ; \mathrm{TI}=500 \mathrm{~ms} ; \mathrm{FA}=20^{\circ} ; 128$ contiguous slices of 1 $\mathrm{mm}$ thickness; FOV $=192 \times 192 \mathrm{~mm}$; in-plane resolution $0.75 \mathrm{~mm}$ ).

\section{Data processing and analysis}

fMRI experiments: visual and haptic object perception. Imaging data were preprocessed and analyzed using Brain Voyager QX (version 2.30; Brain Innovation). Functional data were assessed for head motion and/or magnet artifacts by viewing cine-loop animation and examining motion detection parameter plots after 3D motion correction algorithms on the untransformed 2D data aligned to the functional volume closest in time to the anatomical scan. Assessment of the motion parameters showed only gradual drifts $(<2 \mathrm{~mm}$ within a given run) and no abrupt motion artifacts; therefore, all scans were included in the analyses. Functional data were preprocessed with high-pass temporal filtering to remove frequencies $<3$ cycles/run. Functional volumes were then superimposed on anatomical brain images transformed into Talairach space (Talairach and Tournoux, 1988). For each participant, data were spatially smoothed using a $6 \mathrm{~mm}$ full-width at half maximum Gaussian kernel. A wholevolume voxelwise analysis was performed using the data from all six experimental runs using separate predictor functions for each experimental condition. Predictor functions were generated for the three con- 


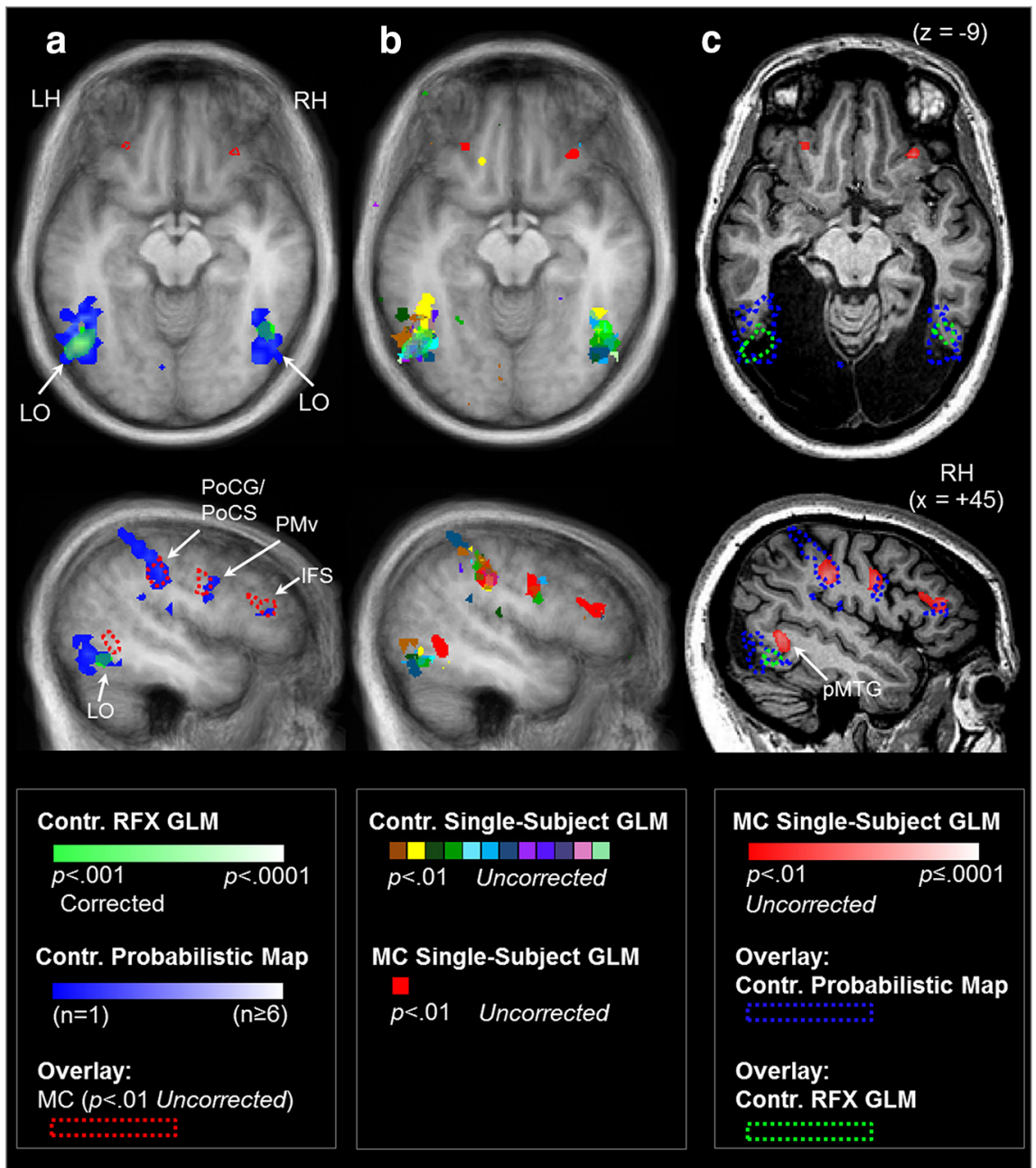

Figure 3. Haptic shape-based activation was consistently observed within LOC in neurologically intact control participants, but not in M.C. Brain areas showing haptic shape-selectivity were identified using a conjunction analysis ([0bject Different $>$ Texture Different] AND [Object Different $>$ 0bject Same] AND [0bject Different + Texture Different + Object Same $>$ Rest]) that isolated areas that were more sensitive to haptic form versus textures and fMR adaptation to haptic shape repetition. To contrast fMR responses to haptically explored objects in M.C. with healthy controls, we computed three types of statistical maps. First, a standard statistical map based on a RFX GLM was computed to isolate voxels that were activated maximally across all controls, thresholded at $p<0.001$ corrected for multiple comparisons ( $\boldsymbol{a}$; shown in green). Second, we computed probabilistic functional maps. In contrast to the RFX GLM analysis, in which activation only reaches statistical significance if there is sufficient spatial overlap between observers, probabilistic functional maps estimate the number of controls who showed activation in a given region and are used here to estimate the spatial boundary within which to expect activation from patient M.C. within LOC. The maps, illustrated in blue in $\boldsymbol{a}$, display the number (from 1 to $\geq 6$ ) or percentage (from $6 \%$ to $\geq 50 \%$ ) of controls that showed activation in each voxel. $\boldsymbol{b}$, Single-subject GLM activation maps of each observer are also displayed, thresholded at $p<0.01$ uncorrected. For comparative purposes, $\boldsymbol{a}$ and $\boldsymbol{b}$ show functional data for all observers (including M.C.; displayed in red) overlaid on the averaged anatomical image of the control group and $c$ displays single-subject GLM data for patient M.C., as well as the spatial extent of RFX GLM activation and probabilistic functional maps for controls (dashed lines) overlaid on patient M.C.'s anatomical image. Functional activation in the top panel is shown in an axial slice plane at the level of peak activation in the LOC in the RFX GLM analysis ( $z=$ $-9)$. Activation in the bottom panel is shown from a sagittal slice plane $(x=+45)$. Although above-threshold shape-selective activation in controls extended anteroventrally beyond the boundary of M.C.'s lesion, M.C. nevertheless did not show activation in the region of LOC using any of the above analysis techniques. M.C., but not controls, showed haptic shape responses more dorsally and anteriorly in right pMTG. Images are shown in neurological format (LH on left side). Contr., Controls.

ditions by convolving a rectangular wave function with a standard hemodynamic response function. Individual fMRI data were analyzed using a single subject general linear model (GLM). Data for each participant were processed using a percent-signal-change transformation and a correction for serial (temporal) autocorrelations.

We compared the pattern of fMRI responses to haptically presented objects shown by patient M.C. with those of healthy controls. Brain areas showing haptic shape selectivity were identified using a conjunction analysis ([Object Different $>$ Texture Different] AND [Object Differ- ent $>$ Object Same] AND [Object Different + Texture Different + Object Same $>$ Rest]). The conjunction isolated areas that were both more sensitive to haptic form than textures and that also showed fMR adaptation to haptic shape repetition. Using the logic of fMRadaptation designs, neural populations that encode object shape are expected to show a reduced fMRI response (i.e., adaptation) on blocks of trials in which shape is repeated compared with blocks in which shape changes across trials (Grill-Spector and Malach, 2001). For patient M.C., the resultant activation map was set to a minimum threshold of $p<0.01$ (uncorrected).

To compare neural activation patterns shown by patient M.C. with those expected in the healthy brain, haptic fMRI responses in the control group were estimated using the following: (1) a whole-volume random effects (RFX) voxelwise analysis of the smoothed group data using a GLM and (2) overlap probability analyses. For the RFX GLM analysis, group activation maps were set to a minimum statistical threshold ( $p<0.001)$. To correct for multiple comparisons, we used a spatial extent approach using Brain Voyager's Cluster Threshold Estimation plug-in, in which Monte Carlo simulations are used (Forman et al., 1995) to calculate the likelihood of obtaining different cluster sizes within the 3D statistical maps (Goebel et al., 2006). A calculated cluster size correction of 13 functional voxels of $3 \mathrm{~mm}^{3}$ each (totaling $351 \mathrm{~mm}^{3}$ or greater) was applied to the group RFX map, ensuring that a global error probability of $p<0.05$ was met. The spatial consistency of haptic shape-selective activity patterns across controls was also quantified by calculating probabilistic functional maps. Probabilistic maps represent the relative number of participants who showed functional activation at a given spatial location (in Talairach space). Probabilistic maps were generated from the subject-specific functional maps from all 12 controls, with the smoothed functional volume data from each observer (averaged across all runs) set to a statistical threshold of $p<0.01$, equivalent to the threshold used to display haptic shape-selective activation patterns in patient M.C. The resultant probabilistic maps display the number (from 1 to $\geq 6$ ) or percentage (from $6 \%$ to $\geq 50 \%$ ) of observers who showed activation in each voxel. For display purposes, the RFX and probabilistic activation maps for the conjunction contrast in controls are displayed on the cortical surface of a representative control participant (green and blue, respectively; Fig. 4, left). We also segmented M.C.'s brain at the boundary between gray and white matter to create a cortical surface representation. Activation for M.C. is mapped to her cortical surface for comparison with controls (Fig. 4, right). We examined all brain areas activated in the conjunction contrast in controls and M.C. in volumetric space to ensure that the surface models were an accurate representation of the underlying activation patterns.

In addition to examining the spatial distribution of neural activation patterns, we compared the pattern and amplitude of MR time series during haptic recognition blocks for controls versus M.C. within the major areas identified in the conjunction contrast [poste- 




Figure 4. Patient M.C. showed a strikingly similar pattern of haptic shape-selective activation in cortical areas outside of the LOC. The left column shows haptic shape-selective fMRI responses in controls displayed on the cortical surface of a representative participant. Activation for the control group based on RFX analysis ( $p<0.001$ corrected) is shown in green and probabilistic functional maps are shown in blue. The right column shows haptic shape-selective fMRI responses in M.C. rendered on her cortical surface ( $p<0.01$ uncorrected; right, activation shown in red). Activation on the cortical surfaces is shown from a lateral viewpoint for the LH (a) and RH (b), as well as ventral (c) and dorsal (d) viewpoints. Dashed lines delineate the approximate boundary of missing tissue in M.C. based on the control surface. Unlike healthy controls, M.C. showed a region of haptic activation ipsilateral to the palpating hand within the pMTG/ posterior superior temporal sulcus (pSTS; visible in $\boldsymbol{b}$ ). This region did not overlap with LOC, as identified in the control group RFX, probabilistic map analyses, or single-subject GLM results (see Fig. 3). CoS, Collateral sulcus; pFus, posterior fusiform sulcus; vOFC, ventral orbitofrontal cortex. 

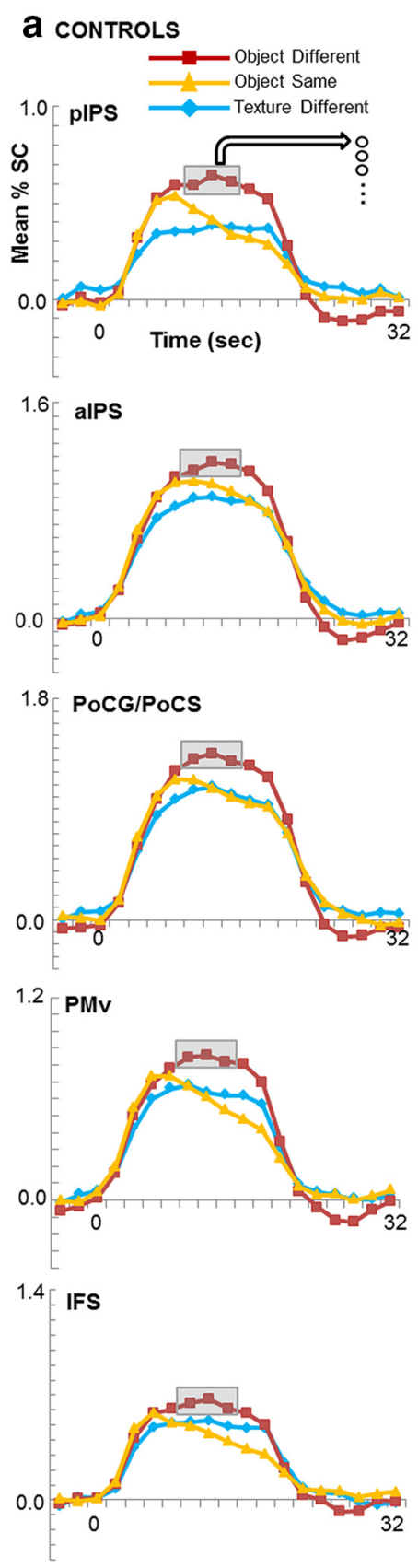

b м.c.

C M.C. vs. CONTROLS
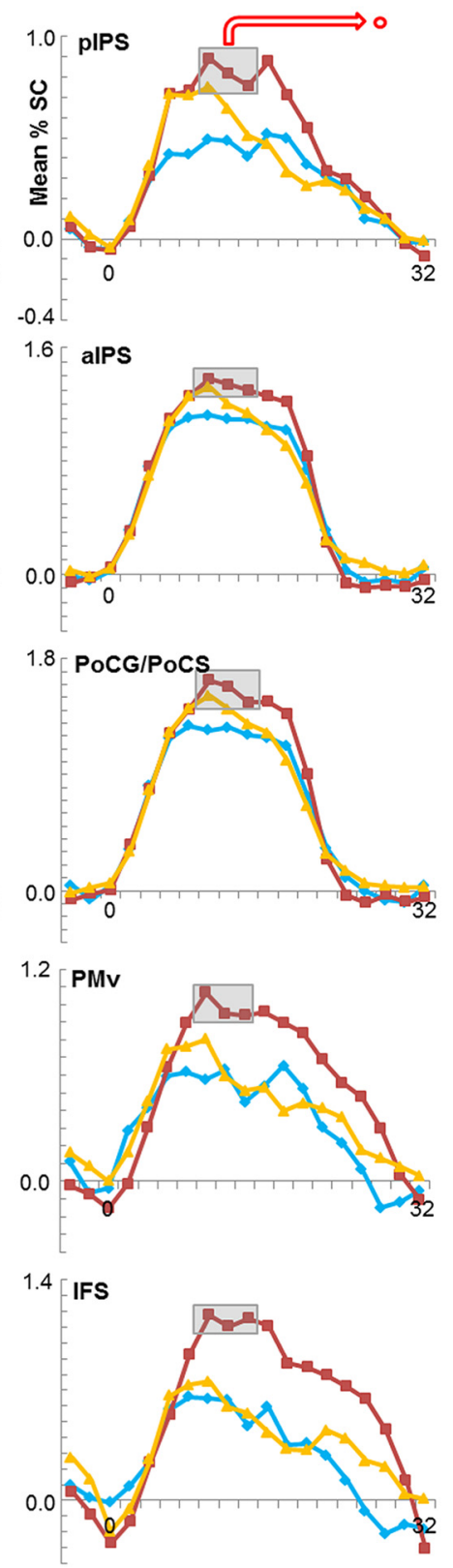
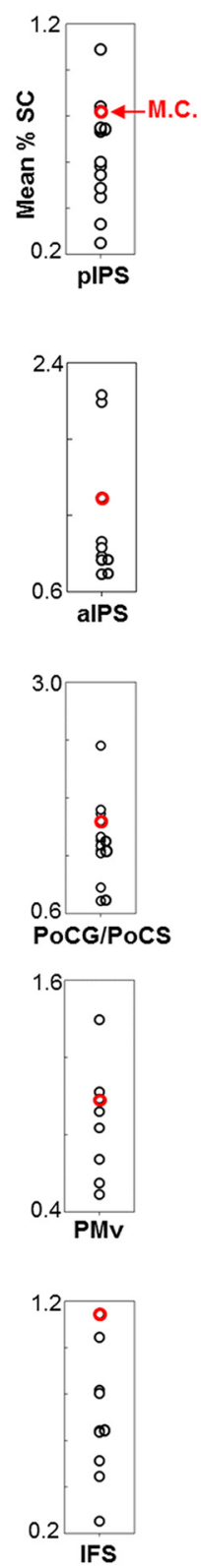

Figure 5. The time course and amplitude of $f M R I$ responses during haptic recognition blocks were comparable between controls (a) and patient M.C. (b). Mean percent signal change (\% SC) patterns over time in the regions identified in the conjunction contrast are shown for each haptic condition (red: object different; yellow: object same; blue: texture different). Vertical point plots (c) display the mean peak fMRI response for each control (black open circles) and patient M.C. (red open circle) from volumes 5-7 in the object different condition, in which peak fMRI responses were observed. The $y$-axis scales are greater on the vertical point plots than the time course graphs to accommodate the spread of peak fMRI responses across individuals. The magnitude of activation in haptic shape-selective areas in M.C. was within the range shown by controls (all $p>0.10$ ). Together, these data suggest a lack of compensatory neuroplastic changes in M.C.'s haptic network despite her lesion to ventral stream visual areas.

rior intraparietal sulcus (pIPS), anterior IPS (aIPS), postcentral gyrus $(\mathrm{PoCG}) /$ postcentral sulcus (PoCS), ventral premotor area (PMv), and inferior frontal sulcus (IFS); Fig. 5] contralateral to the palpating hand, as well as the volume of active cortex in each of these regions (Fig. 6). fMRI response amplitude was calculated as the average percentage signal change for volumes 5-7 in the object different condition (which elicited maximal BOLD responses). The amplitude and volume of activation in each area were contrasted statistically between M.C. and the control sample using Crawford's $t$ tests (Crawford and Howell, 1998; Crawford et al., 2010). Contrasts between volume and amplitude of fMRI responses shown by M.C. versus controls in the five brain areas were evaluated using a statistical significance level of $p=0.01$ (i.e., $0.05 / 5$ ), thereby maintaining the familywise error rate (FWER) at $p=$ 0.05 . For completeness, exact $p$ values of each contrast are reported for each area. Although data are shown for the contralateral hemisphere, comparable responses were observed within analogous regions activated within the ipsilateral hemisphere.

Psychophysical experiments: visual and haptic MLI. The proportion of trials on which the comparison figure was chosen as being longer than the standard was plotted as a function of comparison shaft length. For each observer, a two-parameter cumulative Gaussian function (Eq. 1) was fit to the Müller-Lyer data using regression analysis (Sigmaplot version 10). The inflection point of the Gaussian ( $x_{\mathrm{o}}$ in Eq. 1, corresponding to $50 \%$ probability) was taken as the point of subjective equivalence (PSE), the length (in millimeters) at which an observer was equally likely to judge the comparison as being longer or shorter than the standard. The slope of the curve ( $b$ in Eq. 1 ) was taken as the $\mathrm{SD}$, reflecting within-subject variability. Figure $9 d$ provides for each observer the $R^{2}$ regression coefficients for the fitted functions separately for exploration of the MüllerLyer figures in vision and touch.

$$
y=\frac{1}{1+e^{-\left(\frac{x-x_{o}}{b}\right)}}
$$

The proportion data at each comparison length were averaged across controls and a two-parameter cumulative Gaussian function (Eq. 1) was fit to the averaged data (see Fig. $9 b$ ) to obtain mean PSE and SD parameters. For comparative purposes, illusion magnitude was estimated as a ratio of observed PSE to the length of the standard figure $(30 \mathrm{~mm})$. First, we confirmed that the embedded stimuli generated an illusion in vision and touch in controls. Illusion magnitude was estimated for each observer and sensory modality as a difference score by subtracting the length of the comparison when it was equal to the reference $(30 \mathrm{~mm})$ from the observed PSE. The resulting difference scores for the control group were contrasted against zero using single-sample two-tailed $t$ tests. Paired-samples two-tailed $t$ tests were then used to contrast difference scores in vision versus touch in controls. Finally, two-tailed Crawfords $t$ tests were used to contrast the observed visual and haptic PSE and slope parameters for patient M.C. with the mean and SE PSE and slope parameters observed in the control group.

\section{Results}

First, we examined M.C.'s ability to recognize a large set of everyday objects using vision versus touch. Next, we used fMRI to examine brain areas that showed haptic shape sensitivity in M.C. and contrasted her neural activity with that of 12 age-matched neurologically intact individuals. Despite a severe disruption to 
object recognition using vision, M.C. nevertheless showed a normal ability to recognize objects via touch. Using fMRI, we found that, although M.C. had no spared cortical tissue in the LOC, her pattern, volume, and amplitude of haptic shapeselective responses outside of the lesioned area strongly corresponded with those of healthy controls. Finally, we examined M.C.'s sensitivity to a shape-based illusion in vision and touch. If LOC is critical for perceiving shape (Mancini et al., 2011), then bilateral lesions to LOC should result in a severe attenuation in illusion magnitude in both sensory modalities. M.C. showed no sensitivity to the illusion using vision, but she showed normal psychometric functions when asked to explore the illusion-inducing figures by touch. Our patient data demonstrate that the LOC it is not necessary for haptic shape recognition.

M.C. is unable to recognize objects using vision but can recognize objects via touch

Patient M.C. has extensive lesions affecting bilateral occipitotemporal cortex and right parietal cortex (Fig. 1a; see Materials and Methods). Importantly, M.C.'s lesion includes LOC bilaterally. M.C. was unable to identify any objects using vision alone whether the objects were presented as real-world 3D exemplars (score $0 / 10$ ) or as high-resolution 2D color photographs (score 0/10). Patient M.C. was then blindfolded and asked to complete a series of behavioral tasks designed to tap basic haptic texture and shape recognition abilities. M.C. was able to accurately discriminate between four different grades of sandpaper, describe and identify a series of eight different textured materials (e.g., plastic: "it's smooth but sticky—it's plastic"; velvet: "oh, that's lovely, it's nice and smooth-it feels like velvet") and identify basic shapes of different sizes (circles, squares, and triangles; small, medium, or large). Notably, and in striking contrast to her poor performance on tasks of visual object recognition, M.C. identified and named without error a set of 110 different everyday real-world objects that she explored via touch alone (Fig. $2 a$ ). In a separate shapematching task, we assessed M.C.'s recognition performance for novel 3D clay shapes (James and Kim, 2010). M.C. made no errors in deciding whether the unfamiliar objects were the same or different in shape. M.C.'s haptic recognition times (RTs) (mean $\mathrm{RT}=3.80 \mathrm{~s}, \mathrm{SD}=2.02$ ) were also well within the range of RTs shown by neurologically healthy controls (mean control $\mathrm{RT}=3.34 \mathrm{~s}, \mathrm{SD}=1.90 ; t=0.23, p=0.83$; Fig. $2 b$ ).

\section{Shape-selective fMRI responses to touched objects in M.C. versus healthy controls}

LOC includes a large swath of cortex on the lateral surface of the temporal lobe, including LO, which may itself be composed of two retinotopic subdivisions (Larsson and Heeger, 2006), and the ventral surface of the temporal lobe, including the posterior fusiform sulcus. M.C.'s neural responsivity to visual objects was tested by contrasting fMRI signals to fullcolor photographs of objects with their scrambled counterparts (Malach et al., 1995; Kourtzi and Kanwisher, 2001). In keeping with her lesions, M.C. showed virtually no fMRI activation for visual object stimuli (Fig. $1 b$, left; $p<0.001$, activation shown in orange; $p<0.01$ uncorrected, activation shown in red) and was unable to report any of the stimuli presented during the scan.

We next used fMRI to examine brain regions showing selectivity to haptically presented objects in patient M.C. and compared her fMRI response with 12 neurologically intact agematched controls. Using touch, information is acquired serially and different motoric routines are used for shape versus texture exploration (Lederman and Klatzky, 1993). A contrast of objects versus textures for haptic stimuli may therefore isolate, not only shape-selective areas, but also areas involved in the execution of different motor routines. Therefore, for a brain area to be considered truly shape selective for objects explored via touch, it should show both a greater response for touched objects (which have a shape) versus textures (which do not) and a reduced response (adaptation) when object shape is repeated versus novel. In the latter contrast, activation differences should be driven by shape selectivity because participants always used an active shape exploration strategy and there were no systematic differences be- 
Table 1. Talairach coordinates, size, and maximal statistical significance of clusters identified in the haptic conjunction analysis using the contrast ([0bject Different $>$ Texture Different] AND [0bject Different > Object Same] AND [0bject Different + Texture Different + Object Same > Rest])

\begin{tabular}{|c|c|c|c|c|c|c|c|c|c|c|}
\hline \multirow[b]{3}{*}{ Region } & \multicolumn{5}{|c|}{ Left hemisphere } & \multicolumn{5}{|c|}{ Right hemisphere } \\
\hline & \multicolumn{3}{|c|}{ Talairach coordinates } & \multirow{2}{*}{$\begin{array}{l}\text { Cluster size } \\
\left(\mathrm{mm}^{3}\right)\end{array}$} & \multirow{2}{*}{$\begin{array}{l}\text { Stat max } \\
\text { ( } t \text { value) }\end{array}$} & \multicolumn{3}{|c|}{ Talairach coordinates } & \multirow{2}{*}{$\begin{array}{l}\text { Cluster size } \\
\left(\mathrm{mm}^{3}\right)\end{array}$} & \multirow{2}{*}{$\begin{array}{l}\text { Stat max } \\
\text { (t value) }\end{array}$} \\
\hline & $x$ & $y$ & $z$ & & & $x$ & $y$ & $z$ & & \\
\hline \multicolumn{11}{|c|}{ Controls $(n=12)$ : whole-brain RFX analysis } \\
\hline $\mathrm{LOC}$ & -47 & -65 & -9 & 1441 & 7.17 & 43 & -57 & -8 & 457 & 5.39 \\
\hline $\mathrm{PoCG} / \mathrm{PoCS}$ & -49 & -29 & 30 & 364 & 5.35 & & & & & \\
\hline alPS & -40 & -35 & 48 & 256 & 5.36 & & & & & \\
\hline pIPS & & & & & & 29 & -59 & 45 & 419 & 5.33 \\
\hline \multicolumn{11}{|c|}{ Patient M.C.: single-subject GLM analysis } \\
\hline Thalamus & -16 & -18 & 3 & 31 & & 17 & -16 & 9 & 22 & 2.92 \\
\hline vOFC & -25 & 32 & -12 & 222 & 3.37 & 26 & 28 & -6 & 325 & 3.87 \\
\hline IFS & -42 & 29 & 15 & 44 & 2.85 & 44 & 32 & 19 & 728 & 3.8 \\
\hline PMv (1) & -38 & 4 & 28 & 219 & 3.40 & 40 & -4 & 31 & 1396 & 4.99 \\
\hline $\mathrm{PoCG} / \mathrm{PoCS}$ & -35 & -37 & 40 & 1641 & 4.50 & 38 & -28 & 35 & 3132 & 5.53 \\
\hline PoCG/PoCS_alPS & -33 & -40 & 53 & 3093 & 4.39 & 26 & -43 & 42 & 109 & 3.22 \\
\hline Cingulate gyrus & -6 & -36 & 36 & 30 & 3.23 & 5 & -40 & 33 & 130 & 3.25 \\
\hline Cingulate sulcus & -13 & -22 & 39 & 495 & 4.29 & 12 & -27 & 41 & 76 & 3.28 \\
\hline $\mathrm{PMv}(2)$ & -49 & -8 & 38 & 94 & 3.52 & & & & & \\
\hline Cerebellum (1) & -34 & -36 & -26 & 194 & 3.42 & & & & & \\
\hline Cerebellum (2) & -12 & -74 & -21 & 8 & 2.66 & & & & & \\
\hline pIPS & -23 & -76 & 30 & 940 & 4.48 & & & & & \\
\hline Cingulate gyrus (midline) & 0 & -5 & 38 & 400 & 4.52 & & & & & \\
\hline ParaHG, CoS & & & & & & 35 & -36 & -18 & 816 & 3.64 \\
\hline pMTG & & & & & & 49 & -53 & 1 & 1218 & 4.83 \\
\hline SPL & & & & & & 30 & -56 & 57 & 61 & 2.84 \\
\hline PMd & & & & & & 26 & -22 & 54 & 1258 & 3.53 \\
\hline Calcarine & & & & & & 11 & -68 & 12 & 883 & 3.96 \\
\hline
\end{tabular}

A criterion of $p<0.001$ (corrected) was used for the control group RFX analysis and $p<0.01$ (uncorrected) for the single-subject GLM analysis in patient M.C.

tween the shapes in the repeated and novel conditions. We therefore identified shape-selective networks in our fMRI task using a conjunction analysis that isolated regions showing greater sensitivity to haptically explored objects versus textures and fMR adaptation to repeated object identity (see Materials and Methods).

Based on the conjunction analysis described above, we computed three types of maps for control subjects. First, we calculated a standard statistical $(t>4.32)$ map based on an RFX GLM-a method commonly used to show voxels that are activated most strongly and consistently across a group of observers (shown in green, Figs. 3, 4, left; $p<0.001$ corrected). When comparing a patient with a control group, it is valuable to see, not only the points of maximal activation across the control group, but also to measure the variability in spatial locus of activation within stereotaxically normalized (i.e., Talairach) space from one control participant to another. For example, although some areas of activation of the patient may not overlap with the position of the control group maxima using an RFX analysis, it would be erroneous to conclude that the patient showed a different response pattern from the control group if these areas of activation overlapped with those of one or more individual control participants. Therefore, we examined the spatial consistency of haptic shapeselective activity patterns in controls by calculating probabilistic functional maps (shown in blue, Figs. 3, 4, left) and compared these maps with the fMRI responses observed in M.C. The group probabilistic maps were generated from the smoothed functional maps of each control; the conjunction contrast for each control was set to a statistical threshold of $p<0.01$ (uncorrected) before calculating the overlap probability map. Importantly, this threshold is equivalent to that used to generate functional maps for patient M.C. Finally, we display the single-subject GLM activation maps of each observer overlaid on the average control ana- tomical image (Fig. 3, middle, $p<0.01$ uncorrected). We used a liberal threshold to visualize brain-based responses to haptic object shape because, in M.C., it is important to demonstrate that an absence of (otherwise meaningful) activation cannot be attributable to arbitrary thresholding decisions. For comparative purposes, Figure 3 illustrates the regions of activation in LOC shown by controls using RFX GLM and probabilistic maps overlaid on M.C.'s anatomical image (Fig. 3, right, dashed lines), along with M.C.'s haptic activation from the single-subject GLM. Talairach coordinates of all activated areas are provided in Table 1.

\section{M.C. shows no haptic shape-selective response in LOC}

A RFX GLM contrast in controls revealed strong shape-selective responses in the LOC bilaterally. As expected, all controls showed fMRI responses that were strongest in left LOC contralateral to the palpating right hand (Fig. $3 a$ ). Nine of the 12 controls also showed activation within right LOC; however, these clusters were smaller in size than those on the left. An investigation of the intersubject variability revealed that, although all controls showed activation near the left LOC "hotspot" indicated by the group RFX GLM, there was some scatter in stereotaxic space (Fig. $3 b$ ). To delineate the boundary of the group scatter, we derived probabilistic maps for LOC activation (Fig. $3 a$ ). When we superimposed the boundary encompassing the range of control participants' LOC activation derived using both the RFX and overlap probability maps on M.C.'s brain, at least half of the expected volume fell within areas of M.C.'s brain that, due to her lesion, were devoid of neural tissue (Fig. 3c). Put another way, M.C. showed no activation within the entire search volume expected from the range of LOC activation in controls. Given that we are claiming an absence of activation in LOC in M.C., it is important to emphasize that M.C.'s activation map was thresholded at a 




Figure 7. Patient M.C. showed haptic shape-selective activation in pMTG. A series of consecutive ascending axial slices of posterior occipitotemporal cortex show the separation between haptic shape-selective responses in L0 in controls versus the pMTG response in patient $M . C$. Colored areas show regions identified in the haptic conjunction contrast for each control ( $p=0.01$ uncorrected). In controls, peak LOC responses were observed in the LH (with a maximal response at $z=-9$ in the group-based GLM RFX analysis $(p<0.001$ corrected; Fig. 3). The dashed red line demarcates the haptic fMRI response shown by M.C. in pMTG ( $p=0.01$ uncorrected) overlaid on the average control brain. The pMTG response in M.C. was observed in the $\mathrm{RH}$ and lies anterior and dorsal to the $\mathrm{LO}$ foci observed in controls. Consecutive axial slices are shown across two columns, from ventral (upper left slice, $z=-8$ ) to dorsal (lower right slice, $z=+9)$, with slice positioning shown in Talairach $z$-coordinates. The pMTG response in M.C. is displayed from its most ventral $(z=-7)$ to dorsal $(z=+9)$ extent.

liberal level ( $p<0.01$, uncorrected for multiple comparisons). Therefore, it is unlikely that the absence of activation in LOC is the result of a type II (false-negative) statistical error. Rather, both the overlap of the region with M.C.'s lesion and the absence of activation in the area within remaining tissue indicate that
M.C. has no functional haptic processing within the boundary region of LOC observed in healthy controls.

\section{M.C.'s haptic activation matches controls in areas outside LOC}

Although M.C. differed from controls in that she showed no activation in LOC, she showed strikingly similar haptic shapeselective fMRI responses to controls within other cortical areas (Fig. 4, Table 1). In the controls RFX analysis, haptic shapeselective responses were observed in left aIPS, a grasp-related region located at the junction of the aIPS and the PoCS (Culham and Valyear, 2006; Culham et al., 2006), which is a putative human homolog to that of the monkey (Murata et al., 2000; Sakata, 2003) and has been implicated in visuohaptic crossmodal processing (Grefkes et al., 2002). This activation extended ventrally along somatosensory cortex, along the PoCG and PoCS of the left hemisphere (LH). Patient M.C. showed fMRI responses in the same areas that overlapped with the control RFX data.

Shape-selective activation in the control group RFX analysis was also observed within pIPS in the right hemisphere $(\mathrm{RH})$. Imaging studies in humans frequently report IPS activation on tasks involving haptic object exploration (O'Sullivan et al., 1994; Roland et al., 1998; Deibert et al., 1999; Amedi et al., 2001, 2002; Bodegård et al., 2001; Grefkes et al., 2002; Reed et al., 2004; Zhang et al., 2004; Peltier et al., 2007; Stilla and Sathian, 2008; Tal and Amedi, 2009) and crossmodal visuohaptic processing of object shape or geometric properties (Bodegård et al., 2001; Grefkes et al., 2002; Saito et al., 2003; Zhang et al., 2004; Peltier et al., 2007; Stilla and Sathian, 2008; Tal and Amedi, 2009; Sathian et al., 2011). Neurophysiological data from nonhuman primates also provides strong convergent support for visuohaptic integration within the IPS (Murata et al., 2000). M.C. did not show activation in the same search volume because it corresponded to a region of lesioned tissue-one that extends dorsally along posterior and dorsal IPS in the RH. Patient M.C. did, however, show activation more dorsally in spared tissue within the right superior parietal lobe (SPL) in an area that overlapped with clusters of activation observed in individual control participants (Fig. 4b). Indeed, although there was some scatter of haptic activation between individual observers outside of LOC, there was a striking correspondence between areas of haptic activation in healthy controls using probabilistic maps and the regions of intact cortex of patient M.C. Areas of activation in the control probabilistic maps included PoCG, PoCS, PMv, and IFS, consistent with previous reports (Stilla and Sathian, 2008; Sathian et al., 2011). Smaller regions of activation were also observed in the right dorsal premotor area and anterior ventromedial temporal cortex along the parahippocampal gyri and collateral sulci bilaterally. M.C. showed corresponding activation in these areas where intact tissue was present. Probabilistic maps also revealed bilateral activation in posterior pIPS and along the length of the calcarine sulcus of early visual cortex, consistent with previous reports (Snow et al., 2014). M.C. had lesioned tissue in these areas, however, she showed activation that was confined to the LH in pIPS (as outlined above) and within a small, diamond-shaped region of spared cortical tissue within early visual cortex in the RH.

In summary, the shape-selective network identified here is consistent with data from previous neuroimaging studies and current models of haptic object recognition (Amedi et al., 2002, 2005; James et al., 2005; James et al., 2007; Lacey et al., 2009; James and Kim, 2010; Lucan et al., 2010; Lacey and Sathian, 2011). We found haptic shape-selective fMRI responses in M.C. and controls within parietal cortex (particularly PoCS/PoCG and 


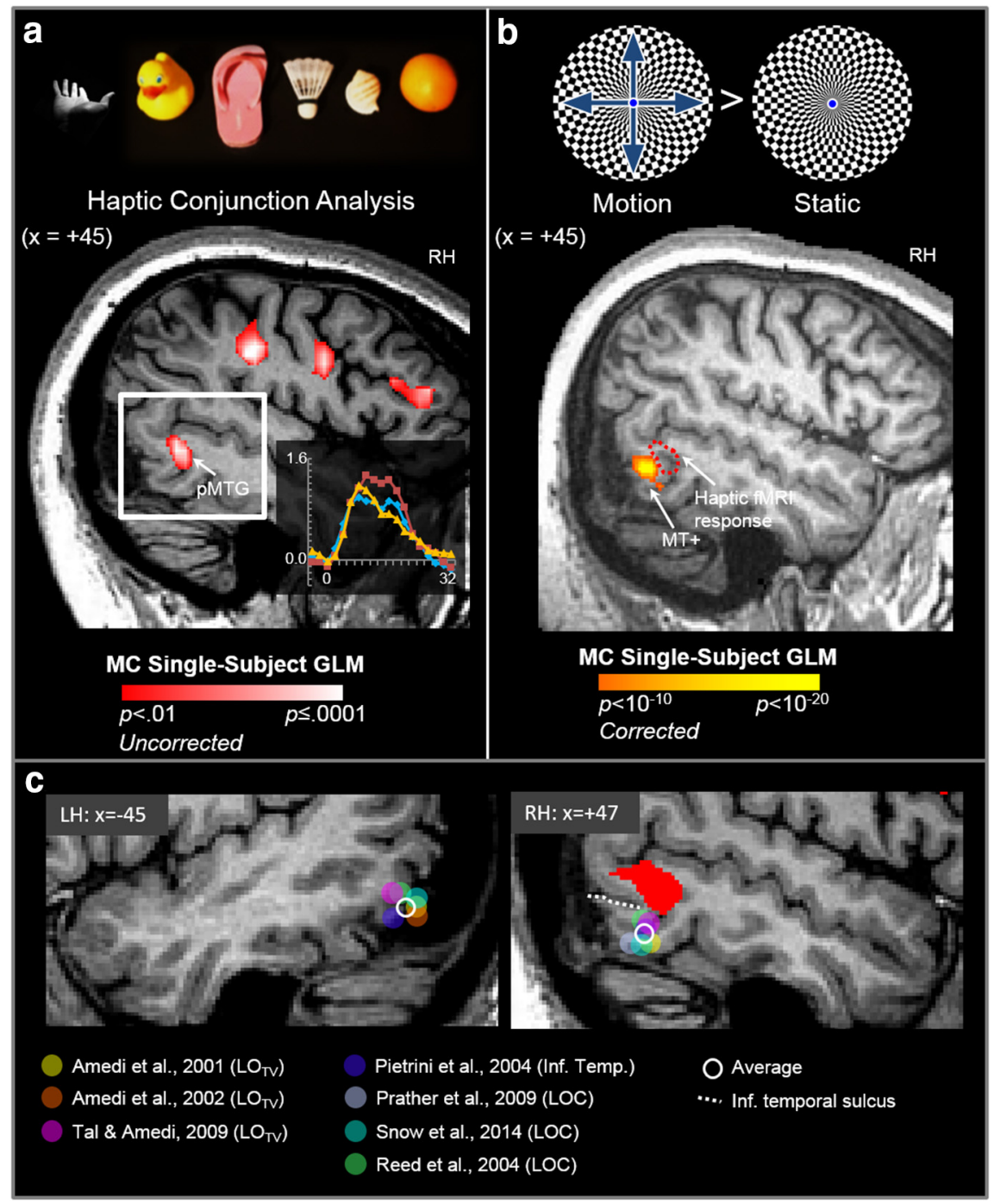

Figure 8. The tactile response in pMTG in patient M.C. lies dorsal to $M T+, L_{T V}$ and $L O C$ foci identified in previous $f M R I$ studies of haptic object perception. $\boldsymbol{a}$, In the haptic conjunction fMRI analysis, we observed a large cluster of activation at the posterior end of the medial temporal gyrus (pMTG) in the RH of patient M.C. The inset (bottom right) shows the time course of activation in the pMTG cluster. $\boldsymbol{b}$, Although M.C. cannot identify stationary objects using vision, she can nevertheless detect motion, a condition known as Riddoch's phenomenon. Accordingly, M.C. showed strong activation in area MT + when she viewed moving versus static checkerboard displays. The haptic shape-related area in pMTG (dotted red line) lies dorsal and anterior to MT + . c, Sagittal slices showing the left and right temporal lobes of M.C.'s brain. The haptic response in right pMTG in M.C. is shown in red ( $p=0.01$ uncorrected). Filled circles (see color key) show the position in Talairach $y$ - and $z$-coordinates of foci of visuohaptic responses in $\mathrm{L} 0_{\mathrm{TV}}$ a putative subregion of $\mathrm{L} O \mathrm{C}$ that responds to both visual and tactile stimuli (as identified by Amedi et al., 2001, 2002, 2009) and responses in LOC and inferior temporal cortex (as identified in previous fMRI studies involving haptic perception of 3D solid objects). Sagittal slices are shown from the average position of peak activation across all studies (LH: $x=-45$, RH: +47$)$. The average position of peak haptic responses in $x-, y$-, and $z$-coordinates across all studies is represented by the open (white) circle. The inferior temporal sulcus (dotted white line) marks the boundary between inferior and middle temporal gyri.

aIPS), PMv, and regions within the lateral frontal cortex (IFS). Controls also showed a strong focus of haptic shape-selective activation in right pIPS (but only more dorsally in SPL in M.C. due to the dorsal extension of her lesion) and in early visual cortex (rostrally in undamaged calcarine tissue in M.C.).

Next, we compared the temporal pattern of BOLD responses of areas activated during the haptic identification blocks, as well as their volume and amplitude, in M.C. versus controls. Figure 5 displays the time course of fMRI responses in areas contralateral to the palpating hand that were identified in patient M.C., with the average time course data for the same areas in controls. M.C.'s activation time courses in pIPS, aIPS, PoCG/PoCS, and IFS were strikingly similar in pattern to those of healthy controls. The mean amplitude of peak fMRI responses in the object different condition (which elicited the strongest BOLD response) in M.C. fell well within normal limits in all areas (all $p$ values $>0.01$, FWER-corrected: $\mathrm{pIPS}, p=$ $0.41 ;$ aIPS, $p=0.39$; PoCG $/$ PoCS, $p=0.63$; PMv, $p=0.59$; IFS, $p=0.10$; Fig. 5, right), indicating that the activated areas were not recruited more strongly in the patient. Similarly, M.C.'s volume of active cortex in each area was within normal limits in all areas (all $p$ values $>0.01$, FWER-corrected: $\mathrm{PMv}, p=$ 0.83 ; IFS, $p=0.81$; pIPS, $p=0.08$; aIPS, $p=$ 0.39 ; and PoCG/PoCS, $p=0.03$; Fig. 6). Together, these data demonstrate fMRI responses of similar pattern, magnitude, and volume in M.C. versus controls and further underscore M.C.'s pattern of unimpaired behavioral haptic recognition performance.

\section{Haptic shape-selective activation in pMTG in M.C.}

Within temporal cortex, M.C. showed a sizeable region $\left(1218 \mathrm{~mm}^{3}\right.$ voxels) of activation within right posterior medial temporal gyrus (pMTG). This contrasts with the general pattern shown by controls, for whom the most robust and consistent fMRI responses were within the region of the LOC in the LH (contralateral to the palpating hand). Indeed, haptic responses in MTG were small and infrequently found in control participants (Fig. 7). Two of 12 controls showed cluster activation that overlapped with the same pMTG search volume as M.C., but these were very small $\left(2 \mathrm{~mm}^{3}\right.$ voxels in one participant, $z=5-6$, and 5 $\mathrm{mm}^{3}$ voxels, $z=-3-0$, in the other) in relation to the sizeable clusters observed within the LOC on the contralateral side (which were 15 and 196 times larger than the more dorsal MTG activation, respectively).

We investigated the position of the pMTG activation in M.C. further by comparing its location relative to motionselective area $\mathrm{MT}+$, as well as regions of LOC that have been shown to respond to tactile (or visuotactile) stimuli in previous fMRI studies (Fig. 8). In normal observers, MT+ responds strongly to moving (versus static) visual patterns (Watson et al., 1993; Dumoulin et al., 2000). Although M.C. cannot identify stationary objects using vision, she can nevertheless detect motion, a condition known as Riddoch phenomenon (Zeki and Ffytche, 1998). We isolated motion-selective area MT+ in M.C.'s brain by measuring fMRI responses during passive viewing of highcontrast moving versus static texture displays (Fig. 8a,b). Despite her severe impairments in vision, M.C. showed robust bilateral fMRI responses to moving visual stimuli in $\mathrm{MT}+$. The cluster of haptic activation in MTG in the RH in M.C. lay adjacent, but slightly superior and anterior to, the MT+. Notably, in neurologically intact participants, LOC typically lies ventrally and posteriorly to MT+ 
(Kourtzi et al., 2002; Valyear and Culham, 2010). A more relevant comparison is with the subregion of LOC that responds to both visual and tactile stimuli, originally named $\mathrm{LO}_{\mathrm{TV}}$ by Amedi et al. (2001). In the visuotactile studies of Amedi and colleagues (Amedi et al., 2001, 2002; Tal and Amedi, 2009), $\mathrm{LO}_{\mathrm{TV}}$ is seen in a variety of configurations relative to $\mathrm{MT}$, including ventral/anterior (Amedi et al., 2002). However, the location of the MTG focus in M.C. is still different from the location of $\mathrm{LO}_{\mathrm{TV}}$ (Amedi et al., 2001, 2002; Tal and Amedi, 2009); it also lies superior to the focus of LOC (Prather et al., 2004, Reed et al., 2004; Snow et al., 2014) and inferior temporal cortex (Pietrini et al., 2004) responses identified in other fMRI studies of haptic object perception (Fig. 8c).

\section{M.C. shows normal sensitivity to the MLI via touch}

Finally, to determine whether the LOC plays a causal role in the MLI, as suggested by TMS data (Mancini et al., 2011), we examined the susceptibility of patient M.C. to the MLI in both in vision and touch. We compared M.C.'s sensitivity to the embedded geometrical figures (Fig. $9 a)$ with a group of seven age-matched controls, all of whom took part in the haptic fMRI study. Sensitivity to the illusion was estimated in vision and touch using regression analysis (see Materials and Methods).

We first examined the magnitude of the MLI in vision and touch for controls. Illusion magnitude was estimated for each observer by subtracting the PSE from the veridical equivalence (i.e., the length of the comparison when it was physically equivalent to the standard). For controls, the MLI occurred in both the visual (mean illusion magnitude $=6.68 \mathrm{~mm}, t_{(6)}=5.46, p=$ 0.002 ) and haptic sensory modalities (mean illusion magnitude $=6.05 \mathrm{~mm}, t_{(6)}=11.47$, $p<0.001$ ) such that the standard figure appeared 1.22 times longer than the comparison in vision and 1.20 times longer than the comparison in touch (Fig. 9b). The magnitude of the MLI was statistically no different between vision and touch in controls $\left(_{(6)}=\right.$ $0.56, p=0.60)$, replicating earlier findings (Frisby and Davies, 1971; Suzuki and Arashida, 1991; Millar and Al-Attar, 2002). However, close inspection of our control data showed that, for most observers, there were discrepancies between the psychometric functions for the visual and haptic MLI (Fig. $9 c, d)$. Linear regression analysis confirmed that the magnitude of an individual's visual PSE was not strongly predictive of haptic PSE $\left(R^{2}=0.17, F=0.99\right.$, $p=0.36$ ). Although the sample size of our control group is modest, these data raise questions about the extent to which the processes

a

b


C
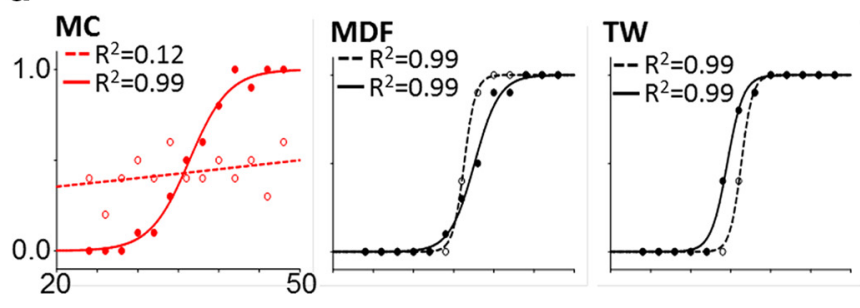

MDM
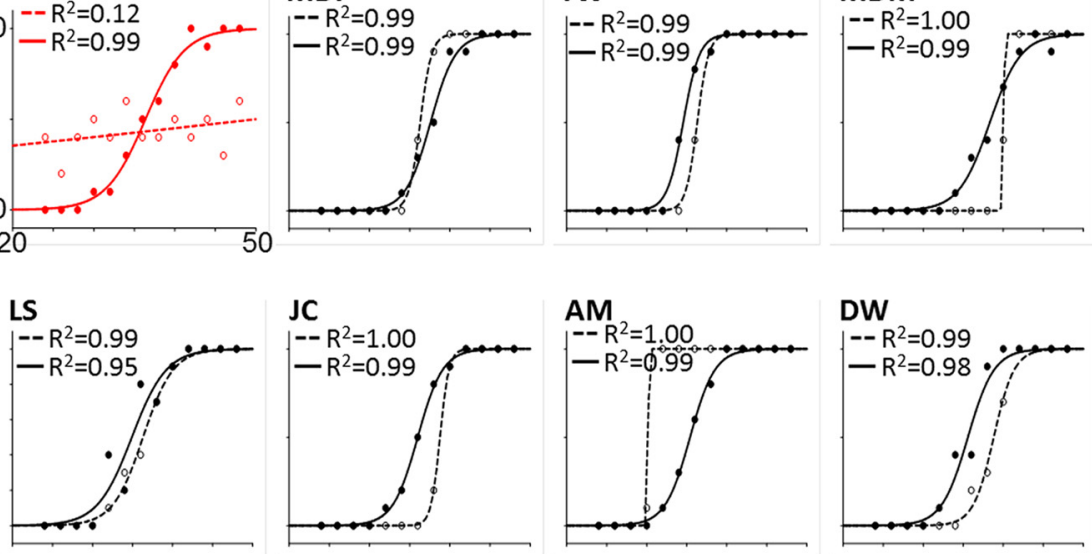

Figure 9. M.C. showed no sensitivity to the MLI in vision, as expected, but she showed a strong haptic MLI that was indistinguishable from that of controls. $\boldsymbol{a}$, The Müller-Lyer stimuli were geometrical figures engraved ( $2 \mathrm{~mm}$ in depth) into 5 square inch dual-color acrylic plates. The horizontal shaft of one figure terminated with inward-pointing arrows (the standard) and the other with outward-pointing arrows (the comparison). The shaft of the standard was $30 \mathrm{~mm}$ in length; the comparison varied randomly across trials from 24 to $48 \mathrm{~mm}$ in increments of $2 \mathrm{~mm}$. On each trial, participants made a two-alternative forced choice as to whether the shaft of the upper figure was longer or shorter than the figure below. In half of the blocks, participants inspected the stimuli using vision only and, in the remaining blocks, participants were blindfolded and explored the figures via touch using the right index finger. $\boldsymbol{b}$, Two-parameter cumulative Gaussian functions fitted to the mean MLI response data for the control group for stimuli explored using vision (dashed black lines) and touch (solid black lines). Overlaid on the control data are M.C.'s ssychometric functions for the MLl in vision (dashed red lines) and touch (solid red lines). The point at which the shaft of the comparison was physically equivalent in length to the standard $(30 \mathrm{~mm})$ is marked by the vertical gray dashed line. The inflection point of the Gaussian (corresponding to 50\% probability; horizontal dashed gray line) was taken as the PSE, the length (in $\mathrm{mm}$ ) at which an observer was equally likely to judge the comparison as being longer or shorter than the standard. c, PSE for individual controls (black circles) and M.C. (red circles). The point at which M.C. perceives the figures as being equal in length is statistically outside the range of controls in vision, but not in touch. $\boldsymbol{d}$, Response data, psychometric functions, and $R^{2}$ regression coefficients for the fitted functions for the visual and haptic MLI for individual control observers (black), and patient M.C. (red). V, Vision; h, haptic.

that underlie shape-based illusions in vision resemble their haptic counterparts (Fisher, 1966).

Next, we contrasted the performance of M.C. with the control group. As expected, M.C. showed virtually no sensitivity to the MLI in vision; the length of the comparison figure had little effect 
on M.C.'s responses $\left(R^{2}=0.12\right.$; see Fig. $\left.9 b-d\right)$. Not surprisingly, M.C.'s visual PSE and slope parameters were markedly different to controls (PSE: control mean $=36.68$, M.C. $=50.02$, Crawford $t=3.85, p=0.008$; slope: control mean $=0.75$, M.C. $=50.02$, Crawford $t=71.44, p<0.00001)$. When exploring the same stimuli via touch, however, M.C. was sensitive to the MLI; her haptic judgments were influenced by the length of the comparison figure and her response data were described well by the regression model $\left(R^{2}=0.99\right)$. Further, statistical contrasts confirmed that M.C.'s haptic PSE and slope parameters were equivalent to those of the control group (PSE: control mean $=$ 36.05 , M.C. $=36.38$, Crawford $t=0.22, p=0.84$; slope: control mean $=1.63$, M.C. $=2.43$, Crawford $t=2.09, p=0.08$ ). Together, our results demonstrate that, although M.C. was not sensitive to the MLI using vision (as expected, due to her extensive lesions), when she was required to explore the stimuli via touch, her susceptibility to the illusion was indistinguishable from that of average data from healthy, sighted control participants.

\section{Discussion}

These neuropsychological, psychophysical, and fMRI data demonstrate that haptic object perception is remarkably spared in a patient with bilateral damage to LOC—an area regarded to be critical for shape recognition in vision and touch. In our haptic conjunction analysis healthy controls showed shape-selective fMRI responses within LOC that were strongest in the LH contralateral to the palpating right hand. These findings verify previous imaging studies documenting LOC involvement in somatosensory object-related tasks (Bonda et al., 1996; Deibert et al., 1999; Amedi et al., 2001, 2002; Grefkes et al., 2002; James et al., 2002; Stoesz et al., 2003; Pietrini et al., 2004; Prather et al., 2004; Reed et al., 2004; Zhang et al., 2004; Amedi et al., 2005; Peltier et al., 2007; Stilla and Sathian, 2008; Allen and Humphreys, 2009; Tal and Amedi, 2009; Kim and James, 2010; Naumer et al., 2010; Kassuba et al., 2011).

Although LOC is consistently activated in the healthy brain during haptic shape recognition, our patient data nevertheless indicate that recognition via touch can proceed without LOC (indeed, with little if any input from the visual system, which is severely compromised in M.C.). Patient M.C. showed a preserved ability to recognize familiar and novel objects via touch, both in accuracy and RT, and normal haptic sensitivity to the MLI. M.C. also showed haptic shapeselective fMRI responses within the same brain areas as neurologically intact controls. Moreover, the time course pattern, amplitude, and size of each activated area were comparable in M.C. and controls. Input from LOC per se does not therefore appear to be necessary for engaging the haptic shape recognition network, which has been shown in previous studies to include IPS, IFS, PMv, and PoCG/ PoCS (Amedi et al., 2002, 2005; James et al., 2005, 2007; Lacey et al., 2009; James and Kim, 2010; Lucan et al., 2010; Lacey and Sathian, 2011).

Whereas controls (but not M.C.) showed robust and consistent LOC activation, M.C. showed fMRI responses to haptically explored objects dorsally and anteriorly to $\mathrm{MT}+$ within right pMTG. Although the MTG activation could reflect abnormal positioning of LOC before the lesion, this seems unlikely for several reasons. First, the haptic MTG response is small and infrequently found in control participants and, when it is found, a separate and larger LOC focus is also apparent (Fig. 7). Second, LOC, as defined visually, typically lies ventral and posterior to $\mathrm{MT}+$, and MT+ lies on the ventral bank of MTG (Kourtzi et al., 2002; Valyear and Culham, 2010). In M.C., the MTG focus clearly lies superior and anterior to MT+ (Fig. 8a,b). Third, and perhaps most importantly, M.C.'s activation in MTG, which is dorsal to the inferior temporal sulcus, lies superior to the location of haptic object-selective $\mathrm{LO}_{\mathrm{TV}}$ (Amedi et al., 2001, 2002, Tal and Amedi, 2009), LOC (Reed et al., 2004; Prather et al., 2004; Snow et al., 2014), and inferior temporal gyrus (Pietrini et al., 2004) foci, as identified in previous fMRI studies of object touch (Fig. 8c). Together, these reasons make it unlikely that the MTG activation in M.C. is a spatially displaced LOC focus. Although the ipsilateral MTG response is consistent with a visual imagery explanation (which requires no haptic shape selectivity whatsoever), a bilateral fMRI response would have been expected.

M.C.'s pMTG activity could reflect postlesion reorganization of LOC-like haptic object coding. During cortical reorganization poststroke, the territory devoted to a given cognitive function typically remaps to neighboring peri-infarct cortical tissue (Murphy and Corbett, 2009). Such reorganization could reflect the recruitment and/or expansion of areas of intact cortical tissue with a similar (but not identical) function to LOC to augment (nevertheless spared) haptic shape-related processing or to recover LOC's critical role in haptic shape encoding. If reorganization of LOC function has indeed taken place in M.C.'s brain, then this represents an unusual case in which sensitivity to the shape of touched objects has remapped, not within healthy tissue bordering the lesion, but more dorsally and anteriorly to MT+ and in the hemisphere ipsilateral (Takatsuru et al., 2009) to the palpating hand. Posterior MTG is understood to represent semantic knowledge about familiar, tool-like objects and how they are used, although LH lateralization is typically reported in fMRI studies in healthy observers (Johnson-Frey, 2004) and in patients with apraxia (De Renzi and Lucchelli, 1988). Interestingly, the pMTG focus in M.C. lies slightly anterior and dorsal to the location of putative "limb-selective" visual cortex in right MTG (positioned at $46,-59,0$, in Talairach space), recently described by Weiner and Grill-Spector (2013). One possibility therefore is that, in M.C., cortical tissue within the region contralateral to tool-selective pMTG in the RH has been reconfigured to facilitate (or recover) haptic shape processing of manipulable objects. If this is the case, it seems especially remarkable that ipsilateral pMTG can restore haptic shape sensitivity to a level that matches the behavioral, neurological, and psychophysical profile of the nondamaged brain.

TMS studies may also provide a test of whether LOC is critical for shape recognition (Siebner et al., 2009), although no studies to date have used bilateral TMS in haptic object recognition tasks. Mancini et al. (2011), however, reported that unilateral rTMS to LOC reduced the magnitude of the haptic MLI in healthy observers. Although Mancini et al.'s (2011) TMS data contrast with our patient findings, in their study, the illusion itself still remained after TMS. The available TMS evidence is therefore not discrepant with the claim tha, although LOC may facilitate haptic perception, object recognition can nevertheless proceed without LOC.

If shape recognition via touch can proceed without LOC, this raises questions about LOC's role in haptic shape processing in neurologically intact individuals. The fact that LOC is consistently recruited during object touch in the healthy brain does not imply that this area is necessary for haptic shape processing because the relationship could be correlational rather than causal. The question therefore follows as to why LOC is so routinely activated during imaging studies of object touch. One explanation is visual imagery; LOC might be recruited because healthy observers visualize object shape during active touch. In other words, it is not that haptic object recognition causes shapeselective recruitment of visual areas; rather, observers invoke vi- 
sual imagery during object touch and it is imagery that causes LOC activity (and possibly also haptic shape-based responses in other early visual areas; Snow et al., 2014). Category-selective regions are routinely activated during visual perception, as well as during mental imagery (O'Craven and Kanwisher, 2000). Mental imagery also elicits meaningful activation patterns within primary visual cortex (Kosslyn et al., 1995; Kosslyn et al., 1999) and activation patterns specific to the shape of imagined objects within LOC (Pietrini et al., 2004; Stokes et al., 2009). Ratings of visual imagery vividness also correlate with the magnitude of haptic shape-selective activation in LOC (Zhang et al., 2004). Based on studies of effective connectivity, Lacey et al. (2009, 2014) have argued that, during haptic shape perception, LOC responses are modulated both by object familiarity and the type of imagery required. Exploring familiar objects by touch elicits object imagery responses in LOC (via top-down inferences about global shape from prefrontal areas), as well as spatial imagery via part-based representations in parietal cortex; for unfamiliar objects, spatial imagery processes are weighted more heavily and LOC interacts with a more extensive network that includes bottom-up inputs from somatosensory cortex and parietal cortex (Lacey et al., 2014). Interestingly, in their revised model of haptic object representation, Lacey et al. (2014) note that parietal cortex is recruited regardless of object familiarity, suggesting that it may be involved in imagery processes or spatial processes unrelated to imagery. Others have argued that haptic shape-based responses in LOC in healthy controls cannot be fully accounted for by visual imagery (Amedi et al., 2001). Similarly, in the early blind, imagery is not a necessary condition for LOC activation (Sathian and Lacey, 2007; Lacey et al., 2009). Early blind individuals, who presumably do not use visual imagery, show occipitotemporal recruitment during Braille reading (Sadato et al., 1996), using visual-to-auditory substitution systems (Amedi et al., 2007), and listening to characteristic sounds of common objects (De Volder et al., 2001).

Finally, LOC activation during haptic object perception could also arise due to feedback from, or network association with, other brain regions that can operate independently from vision, for example, during fine tactile discrimination (Adhikari et al., 2014) or after the retrieval of object information from stored representations in long-term memory (Newman et al., 2005). Indeed, in everyday situations when objects are typically explored using both touch and vision, cross-modal "bootstrapping" should be expected to facilitate object recognition and binding, even though such activity is not necessary for haptic recognition per se. Together, our experiments with patient M.C. demonstrate that familiar everyday objects can be recognized, and haptically driven object-selective neural networks activated, without LOC. It is possible that LOC contributes to haptic recognition by making it more efficient or accurate, particularly during more difficult tasks such as learning the shape of novel objects (James et al., 2005).

\section{References}

Adhikari BM, Sathian K, Epstein CM, Lamichhane B, Dhamala M (2014) Oscillatory activity in neocortical networks during tactile discrimination near the limit of spatial acuity. Neuroimage 91:300-310. CrossRef Medline

Allen HA, Humphreys GW (2009) Direct tactile stimulation of dorsal occipito-temporal cortex in a visual agnosic. Curr Biol 19:1044-1049. CrossRef Medline

Amedi A, Malach R, Hendler T, Peled S, Zohary E (2001) Visuo-haptic object-related activation in the ventral visual pathway. Nat Neurosci 4:324-330. CrossRef Medline
Amedi A, Jacobson G, Hendler T, Malach R, Zohary E (2002) Convergence of visual and tactile shape processing in the human lateral occipital complex. Cereb Cortex 12:1202-1212. CrossRef Medline

Amedi A, von Kriegstein K, van Atteveldt NM, Beauchamp MS, Naumer M] (2005) Functional imaging of human crossmodal identification and object recognition. Exp Brain Res 166:559-571. CrossRef Medline

Amedi A, Stern WM, Camprodon JA, Bermpohl F, Merabet L, Rotman S, Hemond C, Meijer P, Pascual-Leone A (2007) Shape conveyed by visual-to-auditory sensory substitution activates the lateral occipital complex. Nat Neurosci 10:687-689. CrossRef Medline

Benson DF, Greenberg JP (1969) Visual form agnosia: a specific defect in visual discrimination. Arch Neurol 20:82-89. CrossRef Medline

Bodegård A, Geyer S, Grefkes C, Zilles K, Roland PE (2001) Hierarchical processing of tactile shape in the human brain. Neuron 31:317-328. CrossRef Medline

Bonda E, Petrides M, Evans A (1996) Neural systems for tactual memories. J Neurophysiol 75:1730-1737. Medline

Chouinard PA, Whitwell RL, Goodale MA (2009) The lateral-occipital and the inferior-frontal cortex play different roles during the naming of visually presented objects. Hum Brain Mapp 30:3851-3864. CrossRef Medline

Crawford JR, Howell DC (1998) Comparing an individual's test score against norms derived from small samples. The Clinical Neuropsychologist 12:482-486. CrossRef

Crawford JR, Garthwaite PH, Porter S (2010) Point and interval estimates of effect sizes for the case-controls design in neuropsychology: rationale, methods, implementations, and proposed reporting standards. Cogn Neuropsychol 27:245-260. CrossRef Medline

Culham JC, Valyear KF (2006) Human parietal cortex in action. Curr Opin Neurobiol 16:205-212. CrossRef Medline

Culham JC, Cavina-Pratesi C, Singhal A (2006) The role of parietal cortex in visuomotor control: what have we learned from neuroimaging? Neuropsychologia 44:2668-2684. CrossRef Medline

Deibert E, Kraut M, Kremen S, Hart J Jr (1999) Neural pathways in tactile object recognition. Neurology 52:1413-1417. CrossRef Medline

De Renzi E, Lucchelli F (1988) Ideational apraxia. Brain 111:1173-1185. CrossRef Medline

De Volder AG, Toyama H, Kimura Y, Kiyosawa M, Nakano H, Vanlierde A, Wanet-Defalque MC, Mishina M, Oda K, Ishiwata K, Senda M (2001) Auditory triggered mental imagery of shape involves visual association areas in early blind humans. Neuroimage 14:129-139. CrossRef Medline

Dumoulin SO, Bittar RG, Kabani NJ, Baker CL Jr, Le Goualher G, Bruce Pike G, Evans AC (2000) A new anatomical landmark for reliable identification of human area V5/MT: a quantitative analysis of sulcal patterning. Cereb Cortex 10:454-463. CrossRef Medline

Farah MJ (1990) Visual agnosia: disorders of object recognition and what they tell us about normal vision. Cambridge, MA: MIT.

Feinberg TE, Rothi LJ, Heilman KM (1986) Multimodal agnosia after unilateral left hemisphere lesion. Neurology 36:864-867. CrossRef Medline

Fisher GH (1966) A tactile Poggendorff illusion. Nature 212:105-106. CrossRef Medline

Forman SD, Cohen JD, Fitzgerald M, Eddy WF, Mintun MA, Noll DC (1995) Improved assessment of significant activation in functional magnetic resonance imaging (fMRI): use of a cluster-size threshold. Magn Reson Med 33:636-647. CrossRef Medline

Frisby JP, Davies IR (1971) Is the haptic Muller-Lyer a visual phenomenon? Nature 231:463-465. Medline

Goebel R, Esposito F, Formisano E (2006) Analysis of functional image analysis contest (FIAC) data with Brainvoyager QX: From single-subject to cortically aligned group general linear model analysis and selforganizing group independent component analysis. Hum Brain Mapp 27:392-401. CrossRef Medline

Grefkes C, Weiss PH, Zilles K, Fink GR (2002) Crossmodal processing of object features in human anterior intraparietal cortex: an fMRI study implies equivalencies between humans and monkeys. Neuron 35:173184. CrossRef Medline

Grill-Spector K (2003) The neural basis of object perception. Curr Opin Neurobiol 13:159-166. CrossRef Medline

Grill-Spector K, Malach R (2001) fMR-adaptation: a tool for studying the functional properties of human cortical neurons. Acta Psychol (Amst) 107:293-321. CrossRef Medline

Hömke L, Amunts K, Bönig L, Fretz C, Binkofski F, Zilles K, Weder B (2009) 
Analysis of lesions in patients with unilateral tactile agnosia using cytoarchitectonic probabilistic maps. Hum Brain Mapp 30:1444-1456. CrossRef Medline

James TW, Humphrey GK, Gati JS, Servos P, Menon RS, Goodale MA (2002) Haptic study of 3D objects activates extrastriate visual areas. Neuropsychologia 40:1706-1714. CrossRef Medline

James TW, Culham J, Humphrey GK, Milner AD, Goodale MA (2003) Ventral occipital lesions impair object recognition but not object-directed grasping: an fMRI study. Brain 126:2463-2475. CrossRef Medline

James TW, Kim S, Fisher JS (2007) The neural basis of haptic object processing. Can J Exp Psychol 61:219-229. CrossRef Medline

James TW, James KH, Humphrey GK, Goodale MA (2005) Do visual and tactile object representations share the same neural substrate? Mahwah, NJ: Lawrence Erlbaum.

James TW, Kim S (2010) Dorsal and ventral cortical pathways for visuohaptic shape integration revealed using fMRI. In: Multisensory object perception in the primate brain (Naumer MJ, Kaiser JJ, eds.), pp 231-250. New York: Springer.

Johnson-Frey SH (2004) The neural bases of complex tool use in humans. Trends Cogn Sci 8:71-78. CrossRef Medline

Kassuba T, Klinge C, Hölig C, Menz MM, Ptito M, Röder B, Siebner HR (2011) The left fusiform gyrus hosts trisensory representations of manipulable objects. Neuroimage 56:1566-1577. CrossRef Medline

Kim S, James TW (2010) Enhanced effectiveness in visuo-haptic objectselective brain regions with increasing stimulus salience. Hum Brain Mapp 31:678-693. Medline

Konen CS, Behrmann M, Nishimura M, Kastner S (2011) The functional neuroanatomy of object agnosia: a case study. Neuron 71:49-60. CrossRef Medline

Kosslyn SM, Thompson WL, Kim IJ, Alpert NM (1995) Topographical representations of mental images in primary visual cortex. Nature 378:496498. CrossRef Medline

Kosslyn SM, Pascual-Leone A, Felician O, Camposano S, Keenan JP, Thompson WL, Ganis G, Sukel KE, Alpert NM (1999) The role of area 17 in visual imagery: convergent evidence from PET and rTMS. Science 284: 167-170. CrossRef Medline

Kourtzi Z, Kanwisher N (2001) Representation of perceived object shape by the human lateral occipital complex. Science 293:1506-1509. CrossRef Medline

Kourtzi Z, Bülthoff HH, Erb M, Grodd W (2002) Object-selective responses in the human motion area MT/MST. Nat Neurosci 5:17-18. CrossRef Medline

Lacey S, Sathian K (2011) Multisensory object representation: insights from studies of vision and touch. Prog Brain Res 191:165-176. CrossRef Medline

Lacey S, Tal N, Amedi A, Sathian K (2009) A putative model of multisensory object representation. Brain Topogr 21:269-274. CrossRef Medline

Lacey S, Stilla R, Sreenivasan K, Deshpande G, Sathian K (2014) Spatial imagery in haptic shape perception. Neuropsychologia 60:144-158. CrossRef Medline

Larsson J, Heeger DJ (2006) Two retinotopic visual areas in human lateral occipital cortex. J Neurosci 26:13128-13142. CrossRef Medline

Lederman SJ, Klatzky RL (1993) Extracting object properties through haptic exploration. Acta Psychol (Amst) 84:29-40. CrossRef Medline

Lucan JN, Foxe JJ, Gomez-Ramirez M, Sathian K, Molholm S (2010) Tactile shape discrimination recruits human lateral occipital complex during early perceptual processing. Hum Brain Mapp 31:1813-1821. Medline

Malach R, Reppas JB, Benson RR, Kwong KK, Jiang H, Kennedy WA, Ledden PJ, Brady TJ, Rosen BR, Tootell RB (1995) Object-related activity revealed by functional magnetic resonance imaging in human occipital cortex. Proc Natl Acad Sci U S A 92:8135-8139. CrossRef Medline

Mancini F, Bolognini N, Bricolo E, Vallar G (2011) Cross-modal processing in the occipito-temporal cortex: a TMS study of the Muller-Lyer illusion. J Cogn Neurosci 23:1987-1997. CrossRef Medline

Millar S, Al-Attar Z (2002) The Muller-Lyer illusion in touch and vision: implications for multisensory processes. Percept Psychophys 64:353-365. CrossRef Medline

Morin P, Rivrain Y, Eustache F, Lambert J, Courtheoux P (1984) Visual and tactile agnosia. Rev Neurol (Paris) 140:271-277. Medline

Murata A, Gallese V, Luppino G, Kaseda M, Sakata H (2000) Selectivity for the shape, size, and orientation of objects for grasping in neurons of monkey parietal area AIP. J Neurophysiol 83:2580-2601. Medline
Murphy TH, Corbett D (2009) Plasticity during stroke recovery: from synapse to behaviour. Nat Rev Neurosci 10:861-872. CrossRef Medline

Naumer MJ, Ratz L, Yalachkov Y, Polony A, Doehrmann O, van de Ven V, Müller NG, Kaiser J, Hein G (2010) Visuohaptic convergence in a corticocerebellar network. Eur J Neurosci 31:1730-1736. CrossRef Medline

Newman SD, Klatzky RL, Lederman SJ, Just MA (2005) Imagining material versus geometric properties of objects: an fMRI study. Brain Res Cogn Brain Res 23:235-246. CrossRef Medline

O'Craven KM, Kanwisher N (2000) Mental imagery of faces and places activates corresponding stiimulus-specific brain regions. J Cogn Neurosci 12:1013-1023. CrossRef Medline

Ohtake H, Fujii T, Yamadori A, Fujimori M, Hayakawa Y, Suzuki K (2001) The influence of misnaming on object recognition: a case of multimodal agnosia. Cortex 37:175-186. CrossRef Medline

O'Sullivan BT, Roland PE, Kawashima R (1994) A PET study of somatosensory discrimination in man. microgeometry versus macrogeometry. Eur J Neurosci 6:137-148. CrossRef Medline

Peltier S, Stilla R, Mariola E, LaConte S, Hu X, Sathian K (2007) Activity and effective connectivity of parietal and occipital cortical regions during haptic shape perception. Neuropsychologia 45:476-483. CrossRef Medline

Pietrini P, Furey ML, Ricciardi E, Gobbini MI, Wu WH, Cohen L, Guazzelli M, Haxby JV (2004) Beyond sensory images: Object-based representation in the human ventral pathway. Proc Natl Acad Sci U S A 101:56585663. CrossRef Medline

Pitcher D, Charles L, Devlin JT, Walsh V, Duchaine B (2009) Triple dissociation of faces, bodies, and objects in extrastriate cortex. Curr Biol 19: 319-324. CrossRef Medline

Prather SC, Votaw JR, Sathian K (2004) Task-specific recruitment of dorsal and ventral visual areas during tactile perception. Neuropsychologia 42: 1079-1087. CrossRef Medline

Reed CL, Caselli RJ, Farah MJ (1996) Tactile agnosia. Underlying impairment and implications for normal tactile object recognition. Brain 119: 875-888. CrossRef Medline

Reed CL, Shoham S, Halgren E (2004) Neural substrates of tactile object recognition: an fMRI study. Hum Brain Mapp 21:236-246. CrossRef Medline

Riddoch G (1917) On the relative perceptions of movement and a stationary object in certain visual disturbance due to occipital injuries. Proc R Soc Med 10:13-34. Medline

Roland PE, O'Sullivan B, Kawashima R (1998) Shape and roughness activate different somatosensory areas in the human brain. Proc Natl Acad Sci U S A 95:3295-3300. CrossRef Medline

Sadato N, Pascual-Leone A, Grafman J, Ibañez V, Deiber MP, Dold G, Hallett M (1996) Activation of the primary visual cortex by Braille reading in blind subjects. Nature 380:526-528. CrossRef Medline

Saito DN, Okada T, Morita Y, Yonekura Y, Sadato N (2003) Tactile-visual cross-modal shape matching: a functional MRI study. Brain Res Cogn Brain Res 17:14-25. CrossRef Medline

Sakata H (2003) The role of the parietal cortex in grasping. Adv Neurol 93:121-139. Medline

Sathian K, Lacey S (2007) Journeying beyond classical somatosensory cortex. Can J Exp Psychol 61:254-264. CrossRef Medline

Sathian K, Lacey S, Stilla R, Gibson GO, Deshpande G, Hu X, Laconte S, Glielmi C (2011) Dual pathways for haptic and visual perception of spatial and texture information. Neuroimage 57:462-475. CrossRef Medline

Siebner HR, Hartwigsen G, Kassuba T, Rothwell JC (2009) How does transcranial magnetic stimulation modify neuronal activity in the brain? Implications for studies of cognition. Cortex 45:1035-1042. CrossRef Medline

Snow JC, Strother L, Humphreys GW (2014) Haptic shape processing in visual cortex. J Cogn Neurosci 26:1154-1167. CrossRef Medline

Stewart L, Meyer B, Frith U, Rothwell J (2001) Left posterior BA37 is involved in object recognition: a TMS study. Neuropsychologia 39:1-6. CrossRef Medline

Stilla R, Sathian K (2008) Selective visuo-haptic processing of shape and texture. Hum Brain Mapp 29:1123-1138. CrossRef Medline

Stoesz MR, Zhang M, Weisser VD, Prather SC, Mao H, Sathian K (2003) Neural networks active during tactile form perception: common and differential activity during macrospatial and microspatial tasks. Int J Psychophysiol 50:41-49. CrossRef Medline

Stokes M, Thompson R, Cusack R, Duncan J (2009) Top-down activation of 
shape-specific population codes in visual cortex during mental imagery. J Neurosci 29:1565-1572. CrossRef Medline

Suzuki K, Arashida R (1991) Geometrical haptic illusions revisited: Haptic illusions compared with visual illusions. Percept Psychophys 53:329-335. Medline

Takatsuru Y, Fukumoto D, Yoshitomo M, Nemoto T, Tsukada H, Nabekura J (2009) Neuronal circuit remodeling in the contralateral cortical hemisphere during functional recovery from cerebral infarction. J Neurosci 29:10081-10086. CrossRef Medline

Talairach J, Tournoux P (1988) Co-planar stereotaxic atlas of the human brain. New York: Thieme Medical Publishers.

Tal N, Amedi A (2009) Multisensory visual-tactile object related network in humans: insights gained using a novel crossmodal adaptation approach. Exp Brain Res 198:165-182. CrossRef Medline

Valyear KF, Culham JC (2010) Observing learned object-specific functional grasps preferentially activates the ventral stream. J Cogn Neurosci 22:970-984. CrossRef Medline
Watson JD, Myers R, Frackowiak RS, Hajnal JV, Woods RP, Mazziotta JC, Shipp S, Zeki S (1993) Area V5 of the human brain: evidence from a combined study using positron emission tomography and magnetic resonance imaging. Cereb Cortex 3:79-94. Medline

Weidner R, Fink GR (2007) The neural mechanisms underlying the MüllerLyer illusion and its interaction with visuospatial judgments. Cereb Cortex 17:878-884. CrossRef Medline

Weiner KS, Grill-Spector K (2013) Neural representations of faces and limbs neighbor in human high-level visual cortex: evidence for a new organization principle. Psychol Res 77:74-97. CrossRef Medline

Zeki S, Ffytche DH (1998) The Riddoch syndrome: insights into the neurobiology of conscious vision. Brain 121:25-45. CrossRef Medline

Zhang M, Weisser VD, Stilla R, Prather SC, Sathian K (2004) Multisensory cortical processing of object shape and its relation to mental imagery. Cogn Affect Behav Neurosci 4:251-259. CrossRef Medline 